\title{
Salivary levels of putative cariogenic organisms in patients with eating disorders
}

W. A. Bretz ${ }^{1}$, D. D. $\mathrm{Krahn}^{3}$, A. Drewnowski ${ }^{2}$, W. J. Loesche' ${ }^{1}$ Department of Biologic and Materials Sciences. ${ }^{2}$ School of Public Health; and ${ }^{3}$ Department of Psychiatry, University of Michigan, Ann Arbor, U.S.A.

\author{
Bretz WA, Krahn DD, Drewnowski A, Loesche WJ. Salivary levels of putative \\ cariogenic organisms in patients with eating disorders. \\ Oral Microbiol Immunol 1989: 4: 230-232.
}

\begin{abstract}
The present study examined the hypothesis that women with eating disorders associated with a history of chronic vomiting can be characterized by a salivary flora with high levels of aciduric organisms, such as, mutans strepotococci, lactobacilli and yeast. Three groups of female subjects were studied: vomiting bulimics ( $\mathrm{G} 1 ; \mathrm{n}=14)$, and comparison groups selected for high Streptococcus mutans $(\mathrm{G} 2 ; \mathrm{n}=13)$, and low $S$. mutans levels $(\mathrm{G} 3 ; \mathrm{n}=12)$. The prevalence and levels of mutans streptococci, lactobacilli and yeast tended to be higher in bulimics than in non-bulimics. The bulimics had significantly higher levels and higher prevalence of Streptococcus sobrinus than the non-bulimics. A high S. sobrinus colonization may be a marker for a history of vomiting in bulimia.
\end{abstract}

Key words: cariogenic organisms; bulimia

Walter J. Loesche, Department of Biologic and Materials Sciences, School of Dentistry, The University of Michigan, Ann Arbor, MI 48109-1078, U.S.A.

Accepted for publication December 16, 1988
Anorexia nervosa and bulimia are distinctly different eating disorders. Anorexia nervosa, which is most prevalent among adolescent girls, is characterized by extremes of dieting, loss of body weight and a variety of hormonal and neuroendocrine dysfunctions. Bulimia nervosa, which affects women in their early to late twenties, in contrast, is characterized by uncontrollable eating episodes that are followed by fasting, purging, or self-induced vomiting so as to negate the caloric value of the ingested food. Epidemiological studies indicate that about $1 / 100$ is anorexic, while between $5 \%$ and $19 \%$ of college-age women are bulimic $(6,11,12,15)$. Bulimia may comprise a variety of episodic behaviors which may or may not include self-induced vomiting (19). The prevalence of bulimia has been reported as increasing among young women (9, 16), and this has public health implications.

There have been several reports or reviews describing the oral findings in patients with bulimia and/or anorexia nervosa $(5,8,10,17)$. These include dental erosion, low prevalence of dental caries and periodontal disease, parotid swelling, low saliva $\mathrm{pH}$, decreased saliva secretion and buffering capacity. Moreover, a series of case reports have been published in an attempt to illustrate oral manifestations of those eating disorders
$(2,3,14,24)$. None of these investigations, however, has looked at the effect that bulimia and/or anorexia might have upon the microbial composition of the saliva. We hypothesized that the bulimic individuals because of acid regurgitation, might have an oral microbial flora with a high proportion of aciduric organisms, such as the mutans streptococci, lactobacilli and yeast.

\section{Material and methods}

Salivary levels of aciduric organisms were measured in 39 women. This was a university based sample of comparable age and social-demographic status which was further divided into 3 groups: Group $1(\mathrm{n}=14)$ - patients seeking psychological treatment at the Eating Disorders Clinic at the University of Michigan Hospitals; Group $2(n=13)$ a positive control group which had been selected, based on a high level of Streptococcus mutans, i.e., an average of more than $10^{5} \mathrm{~S}$. mutans $/ \mathrm{ml}$ of saliva; Group $3(\mathrm{n}=12)-$ a low S. mutans control group which had an average of less than $10^{5} \mathrm{~S}$. mutans $/ \mathrm{ml}$ of saliva. The average age of the 3 groups was $23.4 \pm 5.7$; $23.4 \pm 5.7$ and $24.5 \pm 6.1$ respectively.

\section{Microbiological procedures}

Stimulated saliva samples (by chewing paraffin) were obtained from all sub- jects. The saliva was dispersed by a vortex mixer for 30 seconds and $0.1 \mathrm{ml}$ was serially diluted at the ratios of 1:10, $1: 100$ and $1: 1000$ in reduced transport fluid and subsequently placed onto three selective culture media by means of a spiral plating system (Spiral Systems, Cinncinnati, OH). TYSB medium (23) for S. mutans and Streptococcus sobrinus, LBS agar (18) for lactobacilli, and Sabouraud dextrose agar (SAB) (Difco Laboratories, Detroit, MI) for yeast, were used as the selective media for these aciduric organisms. After 2 to 3 days of anaerobic incubation at $35^{\circ} \mathrm{C}$ (TYSB and LBS) and aerobic incubation at $37^{\circ} \mathrm{C}(\mathrm{SAB})$, the colony-forming units (CFU) were enumerated, and levels of these organisms per $\mathrm{ml}$ of saliva were calculated. $S$. mutans and $S$. sobrinus could usually be differentiated by colony morphology, but when the identity of a colony was in doubt, raffinose and melibiose were used as confirmatory biochemical tests to discriminate between these species (20).

\section{Clinical and patient investigation}

The number of decayed, missing and filled teeth and surfaces (DMFT and DMFS) was recorded from all patients. Group 1 (G1) patients were asked about their frequency of vomiting, duration of symptoms, the age of onset and usage 
Table 1. Frequency distribution of mutans streptococci, lactobacilli and yeast in saliva of bulimics (G1), high S. mutans (G2) and low S. mutans (G3) subjects

\begin{tabular}{lccc}
\hline & Bulimics & \multicolumn{2}{c}{ Non-bulimics } \\
\hline S. mutans & $\mathrm{G} 1(\mathrm{n}=14)$ & $\mathrm{G} 2(\mathrm{n}=13)$ & $\mathrm{G} 3(\mathrm{n}=12)$ \\
S. sobrinus & $13^{\mathrm{a}}$ & 13 & 10 \\
S. mutans and/or S. sobrinus & $8^{\mathrm{b}}$ & 2 & 3 \\
Lactobacilli & 14 & 13 & 10 \\
Yeast & 9 & 8 & 5 \\
\hline
\end{tabular}

a) number of individuals with detectable levels of aciduric organisms.

b) frequency distribution of $S$. sobrinus in bulimics is significantly different from non-bulimics by the classic chi-square statistic of the fourfold table (alpha $=0.025)$. of antidepressant medication. The diagnosis of anorexia or bulimia nervosa was made on the basis of the DSM-III$\mathrm{R}$ diagnostic criteria (4).

\section{Statistical analysis}

Frequency tables, one-way analysis of variance (ANOVA), simple linear regression analysis, chi-square analysis and independent groups $t$-test were generated using the statistical program SYSTAT (Systat, Evanston, IL).

\section{Results}

The eating disorders group (G1) comprised women with a diagnosis of bulimia nervosa $(n=11)$ and anorexia nervosa with past history of bulimia $(n=$ 3). Because there was no apparent microbiological and clinical differences between bulimics and anorexics they were grouped together as an eating disorder group for statistical analysis.

The frequency distribution of aciduric organisms in the eating disorder patients (G1), high $S$. mutans (G2) and low $S$. mutans (G3) subjects is shown in Table 1. The higher occurrence of $S$. sobrinus in G1 $(8 / 14)$ in contrast with G2 (2/13) and G3 (3/12) suggested that $S$. sobrinus prevalence could differentiate bulimics (G1) from non-bulimics. These differences in distributions were statistically significant by chi-square analysis $(p=0.025)$. Seven of the bulimic subjects that were positive for $S$. sobrinus were colonized by $S$. mutans and all the $S$. sobrinus positive non-bulimic subjects also were colonized by $S$. mutans.

The levels of aciduric organisms per $\mathrm{ml}$ of saliva in the groups were submitted to an analysis of variance (Table 2). The eating disorder group had significantly higher levels of $S$. sobrinus than the control groups. The 8 eating disorder individuals with $S$. sobrinus had
CFU levels above $10^{6} / \mathrm{ml}$ and four subjects had over $10^{7} / \mathrm{ml}$. In contrast the 2 G2 and 3 G3 subjects with $S$. sobrinus had levels below $10^{5} / \mathrm{ml}$ of saliva. Salivary levels of lactobacilli and yeast tended to be higher in the bulimics. However, the low $S$. mutans group had higher levels and prevalence of yeast in their saliva than did the high $S$. mutans group (Tables 1, 2).

The higher levels and occurrence of mutans streptococci in the eating disorder group suggested that these individuals were at risk for developing decay, or that they had experienced more decay than the other groups (G2 and G3). The eating disorder group (G1) had a DMFS of $12.1 \pm 14.1$ which was higher than G3 (DMFS $=7.2 \pm 7.2$ ) but lower than G2 (DMFS $=20.5 \pm 21.9$ ). The overall difference in DMFS scores among G1, G2 and G3 was not statistically significant.

\section{Discussion}

This study is the first to investigate the salivary flora of patients with eating disorders. Our hypothesis that these subjects would have an increased occurrence and levels of aciduric organisms such as the mutans streptococci, lactobacilli and yeast was confirmed (Tables $1,2)$. An unexpected finding was the increased frequency of occurrence of $S$. sobrinus in the salivas of the patients with eating disorders.

There is no obvious explanation why $S$. sobrinus should be uniquely selected for in these patients. S. sobrinus is not as aciduric as $S$. mutans (13), so that frequent acid regurgitation should select for both S. mutans and $S$. sobrinus as indeed was the case (Table 2). S. sobrinus is more dependent than $S$. mutans for sucrose mediated attachment to the pellicle on the tooth surface so that frequent sucrose ingestion would favor its colonization (13).

The prevalence of a high-level mutans streptococci infection in the eating disorders group (G1) could not be associated with active decay since only 2 of 14 women presented with decay, showing 1 and 2 decayed surfaces respectively. This low occurrence of decay is in agreement with other studies $(8,17)$. There may be several explanations for the observed low levels of active decay in patients with bulimia. The mean age of onset (bulimia with vomiting) was 17.0 years \pm 4.6 at which age surfaces susceptible to decay are either past the risk to decay or may have been filled with restorative materials (13). In regard to the placement of restorations, it was possible that this treatment was very recent. Thus, although vomiting may have selected for a mutans streptococci infection, this infection may have been on surfaces no longer at risk to decay. It is also possible that vomiting per se, may have altered the virulence of $S$. mutans and $S$. sobrinus. Likewise it is possible that we were culturing the patients prior to the development of clin-
Table 2. Analysis of variance of bacterial counts ( $\log _{10} \mathrm{CFU} / \mathrm{ml}$ saliva) in bulimics (G1), high $S$. mutans (G2) and low s. mutans (G3) subjects

\begin{tabular}{lcccc}
\hline Group & $\begin{array}{c}\text { S. mutans } \\
\text { Mean } \pm S D\end{array}$ & $\begin{array}{c}\text { S. sobrinus } \\
\text { Mean } \pm S D\end{array}$ & $\begin{array}{c}\text { Lactobacilli } \\
\text { Mean } \pm S D\end{array}$ & $\begin{array}{c}\text { Yeast } \\
\text { Mean } \pm S D\end{array}$ \\
\hline $\begin{array}{l}\mathrm{G} 1 \\
(\mathrm{n}=14)\end{array}$ & $5.78 \pm 1.75^{\mathrm{b}}$ & $3.81 \pm 3.44)^{\mathrm{a}}$ & $3.07 \pm 2.49^{\mathrm{b}}$ & $2.99 \pm 1.72^{\mathrm{b}}$ \\
$\begin{array}{l}\mathrm{G} 2 \\
(\mathrm{n}=13)\end{array}$ & $5.53 \pm 0.71$ & $0.73 \pm 1.78$ & $2.72 \pm 2.31$ & $1.02 \pm 1.63^{\mathrm{b}}$ \\
$\mathrm{G} 3$ & $3.85 \pm 1.82^{\mathrm{b}}$ & $1.32 \pm 2.42$ & $1.32 \pm 1.70^{\mathrm{b}}$ & $3.17 \pm 1.25$ \\
$(\mathrm{n}=12)$ & $\mathrm{p}<0.005$ & $\mathrm{p}<0.01$ & $\mathrm{NS}$ & $\mathrm{p}<0.002$ \\
\hline Anova & & &
\end{tabular}

NS $=$ not significant

a) value in the box is statistically significantly different from other values in the column utilizing Tukey pairwise comparisons at alpha $=0.05$.

b) values with suprascript are significantly different utilizing Tukey pairwise comparisons at alpha $=0.05$. 
ical decay and the high levels of mutans streptococci actually indicated an active infection.

Another possibility is the composition of the food that the bulimics consumed during an eating binge which includes fats as well as sugars, i.e., ice cream, chocolate, cookies, pastries, and other desserts (1). Studies have shown that consumption of fats, e.g., in dairy products has a protective effect on decay $(7,21)$. It may be that the fat content of foods consumed during eating binges exerts a similar protective effect.

There is no simple, objective way to determine whether a bulimic individual is actively emetic other than by supervision, as history taking is unreliable in these individuals. If the finding that the frequency of detection of $S$. sobrinus or that the salivary levels of $S$. sobrinus are consistently elevated in bulimics can be reproduced, then a salivary culture for $S$. sobrinus could have implications for the diagnosis and/or management of certain eating disorders. In this regard it would be necessary to distinguish whether the high salivary $S$. sobrinus levels are a marker for past eating disorders or reflect current emetic activity.

This study has demonstrated that the frequency and levels of $S$. sobrinus was clearly higher in bulimics than in nonbulimics. Although no correlation was found between eating disorders (bulimia) and decay, the identification of these individuals on the basis of a high S. sobrinus colonization, may have implications for both dentists and physicians in the early diagnosis and management of eating disorders. However, future studies utilizing larger numbers of individuals are necessary to confirm these findings.

\section{Acknowledgements}

This study was supported by Public Health Grant DE02731 from the National Institutes of Health.

\section{References}

1. Abraham SF, Beumont PJV. How patients describe bulimia or binge eating. Psychol Med 1982: 12: 625-635.

2. Adler MJ. Atypical caries in bulimia. NY State Dent J 1985: 51: 531-532.

3. Andrews FF. Dental erosion due to anorexia nervosa with bulimia. Br Dent J 1982: 152: 89-90.

4. Diagnostic and statistical manual of mental disorders. Washington, DC: Am Psych Ass, 1987.

5. Clark DC. Oral complications of anorexia nervosa and/or bulimia. J Oral Med 1985: 40: 134-138.

6. Halmi KA, Falk JR, Schwartz E. Bingeeating and vomiting: a survey of a college population. Psychol Med 1981: 11: 697-706.

7. Harper DS, Osborn JC, Clayton R, Hefferren JJ. Modification of food cariogenicity in rats by mineral-rich concentrates from milk. J Dent Res 1987: 66: 42-45.

8. Hellstrom I. Anorexia nervosa: Odontologiske problem. Swed Dent J 1974: 67: 253-269.

9. Herzog DB, Copeland PM. eating disorders. N Engl J Med 1985: 313: 295-303.

10. Hurst PS, Lacey JH, Crisp AH. Teeth, vomiting and diet: a study of the dental characteristics of seventeen anorexia nervosa patients. Postgrad Med J 1977: 53: 298-305.

11. Johnson C, Lewis C, Hagmann J. The syndrome of bulimia: review and synthesis. Psychiat Clin N Am 1984: 7: 247-272.

12. Kendell RE, Hall DJ, Hailey A, Babigian HM. The epidemiology of anorexia nervosa. Psychol Med 1973: 3: 200-203.
13. Loesche WJ. Role of Streptococcus mutans in human dental decay. Microbiol Reviews 1986: 50: 353-80.

14. Miles DA, Gregg BE, Glass BJ, Van-Dis ML. Bulimic erosion. Dental management and report of cases. Can Dent Assoc J 1985: 51: 757-60.

15. Pope HG, Hudson JI, Yurgelun-Todd D. Anorexia nervosa and bulimia among 300 suburban women shoppers. Am J Psychiatry 1984: 141: 292-294.

16. Pyle RL, Halvorsen PA, Neuman PA, Mitchel J. The increasing prevalence of bulimia in freshman college students. Int J Eat Disorders 1986: 5: 631-647.

17. Roberts WB, Li SH. Oral findings in anorexia nervosa and bulimia nervosa: a study of 47 cases. J Am Dent Assoc 1987 115: $407-410$.

18. Rogosa M, Mitchell JA, Wiseman RF. A selective medium for the isolation and enumeration of oral and fecal lactobacilli. J Bacteriol 1951: 62: 132-137.

19. Schotte DE, Stunkard AJ. Bulimia vs bulimic behaviors on a college campus. JAMA 1987: 258: 1213-1215.

20. Shklair IL, Keene HJ. A biochemical scheme for the separation of five varieties of Streptococcus mutans. Arch Oral Biol 1974: 19: 1079-1081.

21. Silva MFA, Burgess RC, Sandham HJ, Jenkins GN. Effects of water-soluble components of cheese on experimental caries in humans. J Dent Res 1987: 66: 38-41.

22. Stege P, Visco-Dangler L, Rye L. Anorexia nervosa: review including oral and dental manifestations. J Am Dent Assoc 1982: 104: 648-652.

23. Van Palenstein-Helderman WH, Ijsseldijk M, Huis I'nt Veld JH. A selective medium for the two major subgroups of the bacterium Streptococcus mutans isolated from human dental plaque and saliva. Arch Oral Biol 1983: 28: 599-603.

24. Wolcott RB, Yager J, Gordon G. Dental sequelae to the binge-purge syndrome (bulimia): report of cases. J Am Dent Assoc 1984: 109: 723-725. 
This document is a scanned copy of a printed document. No warranty is given about the accuracy of the copy. Users should refer to the original published version of the material. 